\title{
NMR Measurement of Identical Polymer Samples by Round Robin Method IV. Analysis of Composition and Monomer Sequence Distribution in Poly(methyl methacrylate-co-acrylonitrile) Leading to Determinations of Monomer Reactivity Ratios
}

\author{
Koichi Hatada, ${ }^{* 1}$ Tatsuki Kitayama, ${ }^{* 1}$ Yoshio Terawaki, ${ }^{* 1}$ Hisaya Sato, ${ }^{* 2}$ \\ Riichiro Chûjô, ${ }^{* 3}$ Yasuyuki TanaKa, ${ }^{* 2}$ Ryozo Kitamaru, ${ }^{* 4}$ \\ Isao ANDo, ${ }^{* 5}$ Kunio HIKICHI, ${ }^{* 6}$ Fumitaka HoRII, ${ }^{* 7}$ and \\ Members of Research Group on NMR, SPSJ ${ }^{\dagger}$ \\ ${ }^{* 1}$ Department of Chemistry, Faculty of Engineering Science, Osaka University, \\ Toyonaka, Osaka 560, Japan \\ *2 Department of Material Systems Engineering, Faculty of Engineering, \\ Tokyo University of Agriculture and Technology, \\ Koganei, Tokyo 184, Japan \\ ${ }^{* 3}$ Department of Material Engineering, The Nishi-Tokyo-University, \\ Uenohara-cho, Kita-Tsuru-gun, Yamanashi 409-01, Japan \\ ${ }^{* 4}$ Faculty of Science and Technology, Ryukoku University, \\ Seta, Ohtsu, Shiga 520-21, Japan \\ *5 Department of Polymer Chemistry, Tokyo Institute of Technology, \\ Ookayama, Meguro-ku, Tokyo 152, Japan \\ *6 Department of Polymer Science, Faculty of Science, Hokkaido University, \\ Sapporo 060, Japan \\ ${ }^{* 7}$ Institute for Chemical Research, Kyoto University, \\ Uji, Kyoto 611, Japan
}

(Received June 12, 1995)

\begin{abstract}
In order to assess the reliability of NMR measurement of polymers, ${ }^{1} \mathrm{H}$ and ${ }^{13} \mathrm{C}$ NMR data for three copolymers of methyl methacrylate (MMA) and acrylonitrile (AN) prepared with AIBN were collected from 46 spectrometers whose resonance frequencies for ${ }^{1} \mathrm{H}$ NMR measurements ranging from 90 to $500 \mathrm{MHz}$. ${ }^{1} \mathrm{H}$ and ${ }^{13} \mathrm{C}$ NMR spectra were measured in nitrobenzene- $d_{5}$ at $110^{\circ} \mathrm{C}$ and acetonitrile- $d_{3}$ at $70^{\circ} \mathrm{C}$, respectively. Standard deviations ( $\sigma$ 's) for chemical shift measurements of the ${ }^{1} \mathrm{H}$ and ${ }^{13} \mathrm{C}$ NMR signals were $0.003-0.008 \mathrm{ppm}$ and $0.03-0.05 \mathrm{ppm}$, respectively. Compositions of the copolymers were determined from the relative intensities of the signals due to the $\mathrm{OCH}_{3}$ (MMA) and $\mathrm{CH}(\mathrm{AN})$ protons, and the $\sigma$ values for the determinations were $3.7-9.5 \%$. The compositions determined from ${ }^{13} \mathrm{C} N M R(\mathrm{C}=\mathrm{O}$ for
\end{abstract}

† Y. Akitomo (Toyobo Co., Ltd.), S. Amiya (Kuraray Central Research Lab.), T. Ashida (Asahi Chemical Industry Co.), N. Fujimoto (Osaka University), Y. Goto (Nippon Oil and Fats Co., Ltd.), A. Higashiyama (Tokyo Institute of Technology), S. Hosoda (Sumitomo Chemical Co., Ltd.), Y. Ikeda (Kyoto Institute of Technology), M. Ikeyama (Japan Synthetic Rubber Co.), T. Imanari (JEOL Ltd.), S. Itoh (Kyoto University), A. Kaji (Toyobo Co., Ltd), T. Kawamura (The University of Tokyo), K. Lee (Osaka University), E. Masuda (Polyplastics Co., Ltd.), K. Matsubara (Mitsubishi Chemical Co.), H. Matsuda (Teijin Tokyo Research Center), M. Mitani (Idemitsu Kosan Co., Ltd.), S. Moriguchi (Showa Denko K.K.), H. Morii (National Institute of Bioscience and Human-Technology), I. Nagoya (Asahi Chemical Industry Co.,), O. Nakagawa (Osaka University), N. Nakanishi (Tosoh Co.), M. Okumura (Toa Nenryo Kogyo Kabushikigaisha), T. Saito (Nippon Oil Co., Ltd.), S. Sawada (Tonen Chemical Co.), T. Sei (Daicel Chemical Industries, Ltd.), I. Seo (Mitsubishi Chemical Co.), T. Shiibashi (Japan Synthetic Rubber Co.), Y. Shimamura (Kanzaki Paper MFG Co., Ltd.), T. Shimamura (Nitto Technical Information Center Co., Ltd.), M. Shimoda (Nippon Zeon Co., Ltd.), K. Sueoka (Tosoh Co.), T. Taguchi (Sanyo Chemical Industry Ltd.), Y. Takai (Osaka University), S. Takemura (Showa Denko K.K.), K. Tanaka (Teijin Tokyo Research Center), and E. Yashima (Kagoshima University). 
${ }^{1} \mathrm{H}$ and ${ }^{13} \mathrm{C}$ NMR Analysis of Poly(MMA-co-acrylonitrile)

\begin{abstract}
MMA unit, $\mathrm{CN}$ for AN unit) agreed well with those obtained from ${ }^{1} \mathrm{H}$ NMR. Monomer reactivity ratios $r_{i j}(i, j=1$ or 2$)$ for a penultimate model were determined from monomer feed ratios and triad fractions obtained from the $\mathrm{C}=\mathrm{O}$ (MMA) and $\mathrm{CH}$ (AN) carbon signals. Most of the $\sigma$ values for $r_{i j}$ determinations were 5-14\%. While $r_{22}$ and $r_{12}$ are nearly equivalent, $r_{11}$ and $r_{21}$ are significantly different from each other, indicating a possible existence of the penultimate-unit effect in the copolymerization of MMA and AN. Terminal model reactivity ratios, $r_{1}$ and $r_{2}$, determined formally from the compositions of three samples by Fineman-Ross method showed large $\sigma$ values $(22-24 \%)$.
\end{abstract}

KEY WORDS Monomer Reactivity Ratio / Radical Copolymerization / Precision / Accuracy / Reliability /

Research group on NMR, the Society of Polymer Science Japan (SPSJ), has made assessments on the reliability of NMR measurements of polymers. In a series of this cooperative research the reliability of chemical shift, signal intensity, spin-lattice relaxation time and nuclear Overhauser enhancement factor has been investigated for ${ }^{1} \mathrm{H}$ and ${ }^{13} \mathrm{C}$ NMR measurements of polymer samples and the results have been reported in this journal. ${ }^{1-3}$

In the present study, ${ }^{1} \mathrm{H}$ and ${ }^{13} \mathrm{C}$ NMR data for three copolymers of methyl methacrylate (MMA) and acrylonitrile (AN) with different copolymer compositions were collected from 46 spectrometers whose resonance frequencies range from 90 to $500 \mathrm{MHz}$ as ${ }^{1} \mathrm{H}$ NMR measurements. The NMR data include chemical shift, spectral resolution and peak intensity. Copolymer compositions and fractions of sequence distribution were calculated from the peak intensities of the spectra. The research work was carried out by several non-members as well as SPSJ members.

The monomer reactivity ratios were evaluated from the compositions and monomer sequence distributions.

\section{EXPERIMENTAL}

Three copolymer samples of MMA and AN with different compositions were prepared in dimethyl sulfoxide (DMSO) at $50^{\circ} \mathrm{C}$ with $2,2^{\prime}$-azobisisobutyronitrile (AIBN) as an initiator. The copolymerizations were terminated at less than $5 \%$ polymer yield (Table I). The resulting copolymers were purified by reprecipitation from DMSO to methanol.

Nitrobenzene- $d_{5}$ and acetonitrile- $d_{3}$ were used as a solvent, respectively, for the ${ }^{1} \mathrm{H}$ NMR measurement and for the ${ }^{13} \mathrm{C}$ NMR measurement. The solutions were filtered under dry nitrogen to remove insoluble materials. The filtered solution of each sample was degassed, and sealed under nitrogen into several $5 \mathrm{~mm}$ NMR sample tubes. Seven sets of six sample tubes (three for ${ }^{1} \mathrm{H}$ measurement and three for ${ }^{13} \mathrm{C}$ measurement) were circulated among collaborating test sites.

The conditions for the ${ }^{1} \mathrm{H}$ and ${ }^{13} \mathrm{C}$ NMR measurements are shown in Table II although the observed range, pulse width, pulse repetition, and number of scans vary to some extent depending on the instrument adopted in the individual research group. The number of spectrometers used was 46; the resonance frequencies for the spectrometers range from 90 to $500 \mathrm{MHz}$ as ${ }^{1} \mathrm{H}$ NMR measurement $(90 \mathrm{MHz} 1 ; 100 \mathrm{MHz} 2 ; 200 \mathrm{MHz} 3 ; 270 \mathrm{MHz}$ 9; $300 \mathrm{MHz}$ 5; $360 \mathrm{MHz} 1 ; 400 \mathrm{MHz} 17 ; 500$ $\mathrm{MHz} 7$ ) and from 22.5 to $125 \mathrm{MHz}$ as ${ }^{13} \mathrm{C}$ NMR measurement $(22.5 \mathrm{MHz} 2 ; 25 \mathrm{MHz} 2$; $50 \mathrm{MHz} 3 ; 67.5 \mathrm{MHz} 8 ; 75 \mathrm{MHz} 5 ; 90 \mathrm{MHz} 1$; $100 \mathrm{MHz} 17 ; 125 \mathrm{MHz} 7$ ).

\section{RESULTS}

\section{Reliability of Chemical Shift Measurement and} Spectral Resolution

${ }^{1} \mathrm{H}$ NMR spectra of copolymer 2 ( $c f$. Table I) measured at 100, 270, 400, and $500 \mathrm{MHz}$ and ${ }^{13} \mathrm{C}$ NMR spectra measured at $100 \mathrm{MHz}$ are 
Table I. Radical copolymerization of MMA and $\mathrm{AN}$ with $\mathrm{AIBN}$ in DMSO at $50^{\circ} \mathrm{C}^{\mathrm{a}}$

\begin{tabular}{|c|c|c|c|c|}
\hline Samnle & MMA & AN & Yield & $\begin{array}{l}\text { MMA units in } \\
\text { copolymer }^{\mathbf{b}}\end{array}$ \\
\hline & $\mathrm{mol}$ & $\mathrm{mol}$ & $\%$ & $\mathrm{~mol}^{\%}$ \\
\hline 1 & 1.016 & 3.908 & 4.85 & 37.5 \\
\hline 2 & 1.715 & 3.225 & 3.71 & 52.0 \\
\hline 3 & 2.712 & 2.235 & 4.27 & 67.1 \\
\hline
\end{tabular}

${ }^{\mathrm{a}}[\mathrm{MMA}+\mathrm{AN}]_{0} \approx 5 \mathrm{moll}^{-1},[\mathrm{MMA}+\mathrm{AN}]_{0} /[\mathrm{AIBN}]_{0}=$ 150. ${ }^{b}$ Determined by ${ }^{1} \mathrm{H}$ NMR spectroscopy. See Table V.

Table II. Conditions for the measurements of NMR spectra

\begin{tabular}{|c|c|c|}
\hline & ${ }^{1} \mathrm{H}$ & ${ }^{13} \mathrm{C}$ \\
\hline Solvent & $\mathrm{C}_{6} \mathrm{D}_{5} \mathrm{NO}_{2}$ & $\mathrm{CD}_{3} \mathrm{CN}$ \\
\hline Conc. $(w / v \%)$ & 5 & 10 \\
\hline Reference & $\mathrm{HMDS}^{\mathrm{a}}$ & $\mathrm{TMS}^{\mathrm{b}}$ \\
\hline $\operatorname{Temp} /{ }^{\circ} \mathrm{C}$ & 110 & 70 \\
\hline Obs. range/ppm & 15 & 250 \\
\hline Pulse width $/^{\circ}$ & 45 & 45 \\
\hline Pulse repetn/s & 10 & 2 \\
\hline Number of scans & 32 & 40000 \\
\hline
\end{tabular}

${ }^{a}$ HMDS, hexamethyldisiloxane. ${ }^{\mathrm{b}} \mathrm{TMS}$, tetramethylsilane.

shown in Figures 1 and 2, respectively, as typical examples. Averaged values of ${ }^{1} \mathrm{H}$ and ${ }^{13} \mathrm{C}$ NMR chemical shifts are listed in Table III together with the standard deviations ( $\sigma$ 's) for chemical shift measurements; the $\sigma$ values were found to be $0.003-0.006$ for ${ }^{1} \mathrm{H}$ NMR and $0.03-0.05 \mathrm{ppm}$ for ${ }^{13} \mathrm{C}$ NMR. The $\sigma$ values for ${ }^{1} \mathrm{H}$ chemical shifts are similar to those obtained in our previous work done in $1982-1983(0.004-0.007 \mathrm{ppm}) .{ }^{1}$ The $\sigma$ values for the ${ }^{13} \mathrm{C}$ chemical shifts decreased greatly as compared with those in the previous work $(0.05-0.31 \mathrm{ppm}) .{ }^{1} \mathrm{~A}$ great improvement in the precision of ${ }^{13} \mathrm{C}$ chemical shift measurements may be due to the quality improvement of ${ }^{13} \mathrm{C}$ NMR instruments. The precisions of chemical shift measurements were independent of resonance frequencies.

The ${ }^{1} \mathrm{H}$ chemical shift of $\mathrm{OCH}_{3}$ group shows a little high-field shift with increasing content

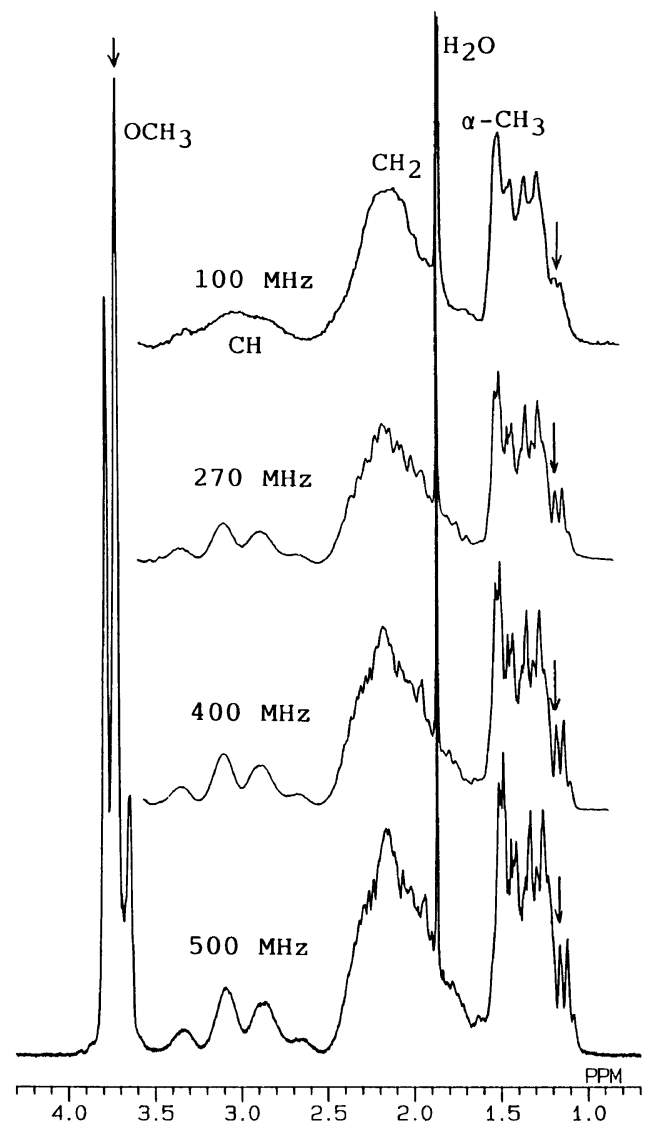

Figure 1. ${ }^{1} \mathrm{H}$ NMR spectra of poly(MMA-co-AN) (sample 2 in Table I) measured at various frequencies in nitrobenzene- $d_{5}$ at $110^{\circ} \mathrm{C}$.

of MMA unit in the copolymers, indicating that the shift depends on the monomer sequence distribution.

In order to express the spectral resolution numerically, two kinds of values have been adopted; resolution index $\mathrm{A}$ expressed by a half-height width of the $\mathrm{OCH}_{3}$ proton signals for ${ }^{1} \mathrm{H}$ NMR ( $c f$. Figure 3 ) or by a peak width at $30 \%$-height of the highest signal of the $\mathrm{C}=\mathrm{O}$ carbon resonances for ${ }^{13} \mathrm{C}$ NMR ( $c f$. Figure 2 ), and the index $\mathrm{B}$ expressed by the ratio of the sum of the heights of two peaks and the height at the lowest point between the two peaks ( $c f$. Figures 2 and 3). Index A represents sharpness of the peak while index B the extent of peak separation (Table IV). Both indices 


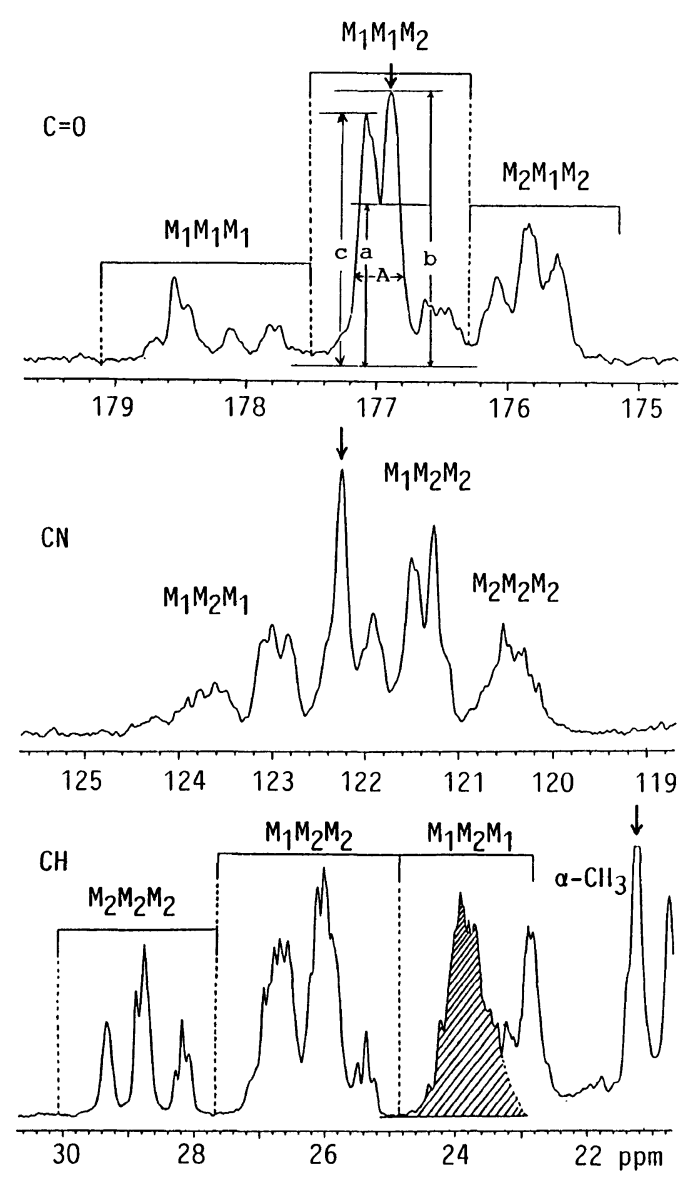

Figure 2. $100 \mathrm{MHz}{ }^{13} \mathrm{C} \mathrm{NMR} \mathrm{spectra} \mathrm{of} \mathrm{poly(MMA-co-}$ AN) (sample 2 shown in Table I). All the signals are sensitive to triads of monomer sequence as indicated in the figure $\left(\mathrm{M}_{1}=\mathrm{MMA}, \mathrm{M}_{2}=\mathrm{AN}\right)$ in acetonitrile- $d_{3}$ at $70^{\circ} \mathrm{C}$. In the $\mathrm{CH}$ region spectrum, the hatched area is assigned to $M_{1} M_{2} M_{1}$ triad according to the literature. ${ }^{6}$

Table III. Average ${ }^{1} \mathrm{H}$ and ${ }^{13} \mathrm{C}$ chemical shifts (ppm) of poly(MMA-co-AN) $)^{\mathrm{a}, \mathrm{b}}$

\begin{tabular}{|c|c|c|c|c|}
\hline & & Sample $1^{\mathrm{c}}$ & Sample $2^{\mathrm{c}}$ & Sample $3^{\mathrm{c}}$ \\
\hline \multirow[t]{2}{*}{${ }^{1} \mathrm{H}$} & $\mathrm{OCH}_{3}$ & $3.736(0.006)$ & $3.728(0.005)$ & $3.719(0.006)$ \\
\hline & $\alpha-\mathrm{CH}_{3}$ & $1.122(0.004)$ & $1.120(0.004)$ & $1.121(0.003)$ \\
\hline \multicolumn{5}{|c|}{$-\cdots-\cdots$} \\
\hline \multicolumn{5}{|c|}{${ }^{13} \mathrm{C} \mathrm{C}=\mathrm{O}$} \\
\hline & $\mathrm{CN}$ & $122.32(0.030)$ & $122.30(0.026)$ & $122.30(0.036)$ \\
\hline & $\alpha-\mathrm{CH}_{3}$ & $21.30(0.039)$ & $21.26(0.035)$ & $21.25(0.051)$ \\
\hline
\end{tabular}

a The peaks whose chemical shifts were determined are indicated in Figures 1 and 2 by arrows. ${ }^{b}$ Figures in parentheses represent standard deviation $\sigma ; \sqrt{\sum\left(x_{i}-\bar{x}\right)^{2} / n}$. ${ }^{\mathrm{c}}$ See Table I.

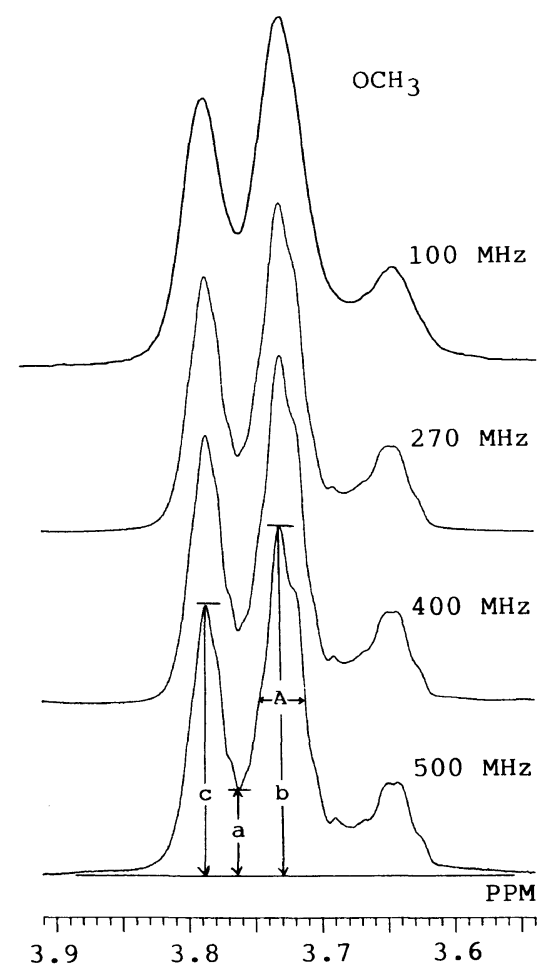

Figure 3. Methoxy proton signals of poly(MMA-co-AN) (sample 2 in Table I) in nitrobenzene- $d_{5}$ at $110^{\circ} \mathrm{C}$.

were almost independent of the magnetic field strength.

\section{Accuracy and Precision of the Temperature of Measurement}

The temperature of NMR measurement is usually indicated by that around the sample tube in an NMR probe, not by the temperature of the sample solution itself. However, these two temperature values sometimes differ from each other, depending on the instrument, sample tube or solvent. Moreover, the temperature around the tube in the probe sometimes deviated a little from that indicated on the set-in thermometer of a spectrometer and also scatters. In order to study these problems, the chemical shift of water contained incidentally in the sample solutions in small amounts, was determined for all the samples measured by each instrument since the chemical shift is sensitive to the temperature of the solution. 
Table IV. Spectral resolution for ${ }^{1} \mathrm{H}$ and ${ }^{13} \mathrm{C}$ NMR spectra of poly(MMA-co-AN) (sample 2 in Table I) ${ }^{\mathrm{a}}$

\begin{tabular}{|c|c|c|c|c|c|c|}
\hline \multirow{2}{*}{\multicolumn{2}{|c|}{ Frequency $/ \mathrm{MHz}$}} & \multirow{3}{*}{$n^{\mathbf{b}}$} & \multicolumn{4}{|c|}{ Resolution indices ${ }^{\mathfrak{c}}$} \\
\hline & & & \multicolumn{2}{|c|}{ Index $\mathrm{A} / \mathrm{ppm}$} & \multicolumn{2}{|c|}{ Index $\mathrm{B}[a /(b+c)]$} \\
\hline${ }^{1} \mathrm{H}$ & ${ }^{13} \mathrm{C}$ & & $\mathrm{OCH}_{3}$ & $\mathrm{C}=\mathrm{O}$ & $\mathrm{OCH}_{3}$ & $\mathrm{C}=\mathrm{O}$ \\
\hline 100 & 25 & 2 & $0.038(11.9)$ & $0.403(3.0)$ & $0.178(19.1)$ & $0.332(14.3)$ \\
\hline 200 & 50 & 3 & $0.039(3.1)$ & $0.363(0.2)$ & $0.218(36.6)$ & $0.256(3.2)$ \\
\hline 270 & 67.5 & 9 & $0.038(10.0)$ & $0.392(5.2)^{d}$ & $0.160(22.7)$ & $0.316(12.2)^{\mathrm{d}}$ \\
\hline 300 & 75 & 5 & $0.036(6.7)$ & $0.380(8.2)$ & $0.135(24.0)$ & $0.317(18.8)$ \\
\hline 400 & 100 & 16 & $0.033(4.7)$ & $0.380(3.6)$ & $0.123(10.9)$ & $0.297(6.5)$ \\
\hline 500 & 125 & 7 & $0.037(9.5)$ & $0.380(3.0)$ & $0.147(17.9)$ & $0.299(11.9)$ \\
\hline
\end{tabular}

${ }^{a}$ Figures in parentheses represent standard deviation $\sigma(\%) ; 100 \sqrt{\sum\left(x_{i}-\bar{x}\right)^{2} / n} / \bar{x}$. ${ }^{b}$ Number of determinations. ${ }^{\mathrm{c}}$ See text and Figures 2 and 3. ${ }^{\mathrm{d}}$ Data from eight determinations.

The concentration of the water in each sample solution was found to be almost the same $\left(0.039-0.045 \mathrm{moll}^{-1}\right)$ from its peak intensity for all of the samples studied.

The relationship between the chemical shift of the water and the temperature of the sample solution was determined for the individual test samples from the ${ }^{1} \mathrm{H}$ NMR measurement at one of the test sites (Hatada's laboratory) using a $100 \mathrm{MHz}$ NMR spectrometer (JNMFX100). Using the calibration curve thus obtained for each sample, the temperature of the sample solution at each ${ }^{1} \mathrm{H}$ NMR measurement was evaluated from the chemical shift of the water. The range and averaged values of the temperature for three sample solutions were determined for each spectrometer and are shown in Figure 4. The fluctuation of the temperatures for three sample solutions installed in a given spectrometer were within $\pm 1.0^{\circ} \mathrm{C}$ with a few exceptions; the fluctuation seems to be more enhanced somewhat in the instruments with higher magnetic strength. However, the averaged values of the solution temperatures for respective instruments were in the range from 103.5 to $118.3^{\circ} \mathrm{C}$ although the averaged value for all the instruments $\left(110.3^{\circ} \mathrm{C}\right)$ was almost the same as the temperature set on the instrument; $110^{\circ} \mathrm{C}$ (Figure 4). These results of temperature fluctuation should be noted, particularly in the case of the

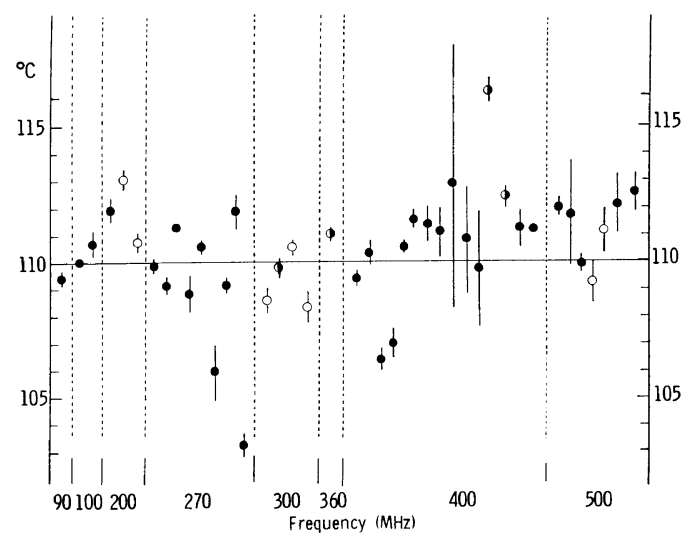

Figure 4. Accuracy and precision of the temperature of measurement of NMR spectrum. (O) JEOL; (†) Bruker; (O) Varian. The vertical lines represent the scatter of the temperatures of sample solutions.

sample whose chemical shifts are temperaturedependent.

\section{Analysis of Copolymer Composition}

Copolymer compositions of the poly(MMAco-AN)s were determined from the relative intensities of the signals due to the methoxy methyl protons of MMA units and the methine proton of AN units. As a typical example, $500 \mathrm{MHz}{ }^{1} \mathrm{H}$ NMR spectra of three copolymer samples (see Table I) are shown in Figure 5. The copolymer compositions determined from the ${ }^{1} \mathrm{H}$ NMR spectra measured at different resonance frequencies are shown in Table $\mathrm{V}$. 


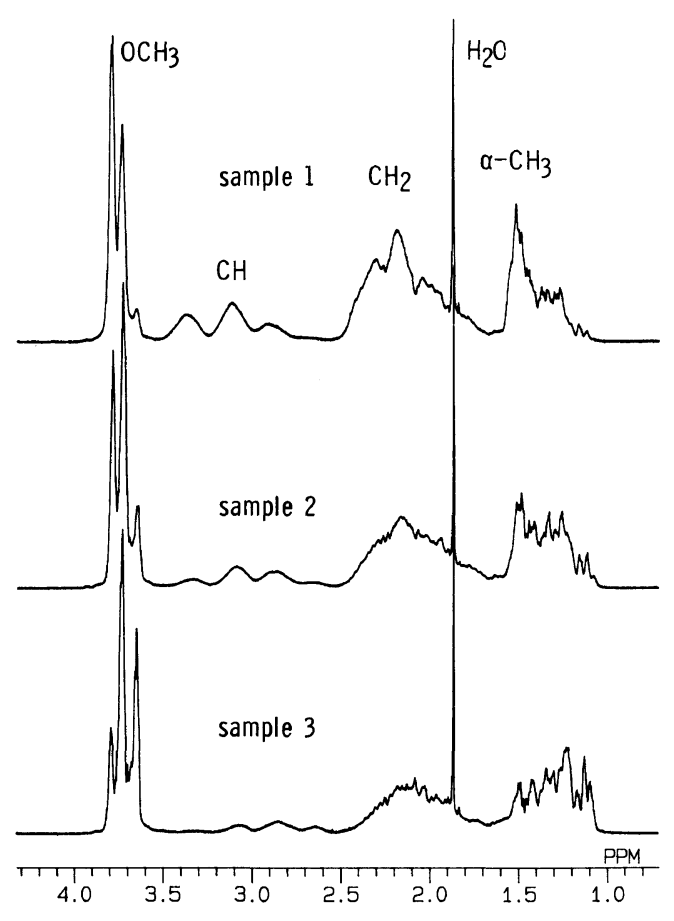

Figure 5. $500 \mathrm{MHz}{ }^{1} \mathrm{H}$ NMR spectra of poly(MMA-coAN)s (samples $1-3$ in Table I) in nitrobenzene- $d_{5}$ at $110^{\circ} \mathrm{C}$.

Table V. Compositional analysis of poly(MMA-co-AN) by ${ }^{1} \mathrm{H}$ NMR spectroscopy ${ }^{\mathrm{a}}$

\begin{tabular}{|c|c|c|c|c|}
\hline \multirow{2}{*}{ Freq./MHz } & \multirow{2}{*}{$n^{\mathrm{b}}$} & \multicolumn{3}{|c|}{ MMA contents of copolymer $/ \mathrm{mol} \%$} \\
\hline & & Sample 1 & Sample 2 & Sample 3 \\
\hline 90 & 1 & $36.4(-)$ & $50.1(-)$ & $65.2(-)$ \\
\hline 100 & 2 & $35.0(0.69)$ & 48.4 ( 1.34$)$ & $62.4(2.56)$ \\
\hline 200 & 3 & $36.7(2.16)$ & $56.5(14.6)$ & $67.5(5.36)$ \\
\hline 270 & 9 & $38.0(3.39)$ & $51.7(2.34)$ & $68.2(3.70)$ \\
\hline 300 & 5 & $36.9(3.77)$ & $51.1(4.29)$ & $67.8(2.57)$ \\
\hline 360 & 1 & $36.8(-)$ & $55.9(-)$ & $68.9(-)$ \\
\hline 400 & 17 & $37.6(3.05)$ & $52.7(11.3)^{\mathrm{c}}$ & $67.8(9.02)^{\mathrm{c}}$ \\
\hline 500 & 7 & $38.2(3.99)$ & $53.5(9.01)$ & $68.5(5.88)$ \\
\hline average & 45 & $37.5(3.72)$ & $52.0(9.45)$ & $67.1(6.66)$ \\
\hline$C-13^{d}$ & 23 & $36.1(4.39)$ & 49.9 ( 3.90$)$ & $65.2(3.07)$ \\
\hline
\end{tabular}

${ }^{\text {a }}$ Figures in parentheses represent standard deviation $\sigma$ (\%); $100 \sqrt{\sum\left(x_{i}-\bar{x}\right)^{2} / n} / \bar{x}$. 'b Number of determinations. ${ }^{\mathrm{c}}$ Data from sixteen determinations. ${ }^{\mathrm{d}}$ Averaged values for determinations by ${ }^{13} \mathrm{C}$ NMR spectroscopy at different frequencies $(22.5-125 \mathrm{MHz})$.
The $\sigma$ values for the composition determinations were $0.7-9.0 \%$. The $\sigma$ values for sample 1 were smaller than those for samples 2 and 3 , which have smaller AN contents than sample 1. Larger $\sigma$ values for samples 2 and 3 may be due to the fact that the methine proton signals are broad multiplets. It is noteworthy that the precision is higher in the measurements at $100 \mathrm{MHz}$ though the number of determination is only two. It is also notable that the precision attained at 400 and $500 \mathrm{MHz}$ is rather poor.

The copolymer compositions were also determined from the signal intensities of the carbonyl(MMA) and cyano(AN) carbons ( $c f$. Figure 2). The average values thus obtained are in good agreement with those obtained from ${ }^{1} \mathrm{H}$ NMR (Table V).

\section{Analysis of Comonomer Sequence Distribu- tion-Penultimate Model Reactivity Ratio $r_{i j}$ by Chûjô's Single Sample Method \\ Chûjô ${ }^{4}$ has derived a formula to obtain} monomer reactivity ratios from a single sample with the aid of NMR data for the sequence distribution. Chûjô and his colleagues ${ }^{5}$ applied it to MMA-AN copolymerization system. ${ }^{13} \mathrm{C}$ NMR spectra of the copolymer of MMA and $\mathrm{AN}$ are sensitive to the monomer sequence distribution as indicated in Figure 2. The peak assignments for the MMA-centered and AN-centered triads were made according to the literature. ${ }^{6}$ The fractions of the six triads of monomer sequences were determined from the carbonyl(MMA) and methine(AN) carbon signals as shown in Table VI.

The monomer reactivity ratios for the penultimate model, $r_{i j}(i, j=1$ or 2 ), could be determined from the initial monomer ratio and the triad fractions using the following equations developed by Chûjô et al. ${ }^{4,5}$ The $r_{i j}$ values can be calculated from triad fractions of a single copolymer sample.

$$
r_{11}=\frac{\left[\mathrm{M}_{2}\right]_{0}}{\left[\mathrm{M}_{1}\right]_{0}} \cdot \frac{2\left(\mathrm{M}_{1} \mathrm{M}_{1} \mathrm{M}_{1}\right)}{\left(\mathrm{M}_{1} \mathrm{M}_{1} \mathrm{M}_{2}\right)},
$$




\section{K. HATADA et al.}

Table VI. Analysis of monomer sequence distribution in poly(MMA-co-AN) by ${ }^{13} \mathrm{C}$ NMR spectroscopy

\begin{tabular}{|c|c|c|c|c|c|c|c|c|}
\hline \multirow{2}{*}{ Sample } & \multicolumn{4}{|c|}{$\mathbf{M}_{1}-$ Centered triad $/ \%$} & \multicolumn{4}{|c|}{$\mathbf{M}_{2}$-Centered triad $/ \%$} \\
\hline & $n^{\mathrm{b}}$ & $\mathrm{M}_{1} \mathrm{M}_{1} \mathrm{M}_{1}$ & $M_{1} M_{1} M_{2}$ & $\mathbf{M}_{2} \mathbf{M}_{1} \mathbf{M}_{2}$ & $n^{\mathrm{b}}$ & $\mathbf{M}_{1} \mathbf{M}_{2} \mathbf{M}_{1}$ & $\mathbf{M}_{1} \mathbf{M}_{2} \mathbf{M}_{2}$ & $\mathbf{M}_{2} \mathbf{M}_{2} \mathbf{M}_{2}$ \\
\hline 1 & 45 & $7.6(29.2)$ & $41.6(4.2)$ & $50.8(5.0)$ & 46 & $19.0(5.5)$ & $49.0(1.8)$ & $32.0(3.2)$ \\
\hline 2 & 45 & $17.0(6.8)$ & $51.6(2.5)$ & $31.4(7.0)$ & 46 & $37.1(4.0)$ & $47.9(2.4)$ & $15.0(6.9)$ \\
\hline 3 & 44 & $35.0(6.0)$ & $51.0(3.4)$ & $14.0(11.3)$ & 45 & $58.5(4.5)$ & $35.9(5.3)$ & $5.7(22.3)$ \\
\hline
\end{tabular}

${ }^{\mathrm{a}}$ Figures in parentheses represent standard deviation $\sigma(\%) ; 100 \sqrt{\sum\left(x_{i}-\bar{x}\right)^{2} / n} / \bar{x} .{ }^{\mathrm{b}}$ Number of determinations.

$$
\begin{gathered}
r_{21}=\frac{\left[\mathrm{M}_{2}\right]_{0}}{\left[\mathrm{M}_{1}\right]_{0}} \cdot \frac{\left(\mathrm{M}_{1} \mathrm{M}_{1} \mathrm{M}_{2}\right)}{2\left(\mathrm{M}_{2} \mathrm{M}_{1} \mathrm{M}_{2}\right)} \\
r_{12}=\frac{\left[\mathrm{M}_{1}\right]_{0}}{\left[\mathrm{M}_{2}\right]_{0}} \cdot \frac{\left(\mathrm{M}_{1} \mathrm{M}_{2} \mathrm{M}_{2}\right)}{2\left(\mathrm{M}_{1} \mathrm{M}_{2} \mathrm{M}_{1}\right)} \\
r_{22}=\frac{\left[\mathrm{M}_{1}\right]_{0}}{\left[\mathrm{M}_{2}\right]_{0}} \cdot \frac{2\left(\mathrm{M}_{2} \mathrm{M}_{2} \mathrm{M}_{2}\right)}{\left(\mathrm{M}_{1} \mathrm{M}_{2} \mathrm{M}_{2}\right)} \\
\left(\mathrm{M}_{1}=\mathrm{MMA}, \mathrm{M}_{2}=A N\right)
\end{gathered}
$$

Averaged $r_{i j}$ values for three copolymer samples are shown in Table VII. Most of the $\sigma$ values for $r_{i j}$ were around $10 \%$. Larger $\sigma$ values for $r_{11}$ of sample 1 and for $r_{22}$ of sample 3 could be ascribed to smaller peak intensities for the $M_{1} M_{1} M_{1}$ triad and the $M_{2} M_{2} M_{2}$ triad, respectively. The $r_{11}$ value is different from the $r_{21}$ for all samples. This is a clear indication of a significant penultimate-group effect characteristic of the chain-end MMA radical. It has been reported that the copolymerization of MMA and AN can not be described with the terminal model. ${ }^{5-7}$ Both the $r_{11}$ and $r_{21}$ values, particularly the former, decreased with an increase in the content of MMA units in the copolymer. This suggest a possible existence of pre-penultimate effect in the reactivity of $\sim \mathrm{M}_{1} \mathbf{M}_{1} \cdot$ radical.

On the other hand, the values of $r_{12}$ and $r_{22}$ were very close to each other, both being enhanced slightly with increasing MMA content in the copolymer. Such a composition dependence of $r_{12}$ and $r_{22}$ was also found in the additional experiments on another series of copolymers having a wider range of composition. The increase of $r_{12}$ and $r_{22}$ was very clearly evidenced especially in the compositional
Table VII. Penultimate model reactivity ratios $r_{i j}$ for the copolymerization of MMA $\left(\mathrm{M}_{1}\right)$ and $\mathrm{AN}\left(\mathrm{M}_{2}\right)$ in DMSO at $50^{\circ} \mathrm{C}^{\mathrm{a}}$

\begin{tabular}{ccccc}
\hline Sample & \multicolumn{1}{c}{$r_{11}$} & $r_{21}$ & $r_{12}$ & $r_{22}$ \\
\hline 1 & $1.44(26.8)$ & $1.56(7.9)$ & $0.34(7.0)$ & $0.34(4.8)$ \\
2 & $1.24(13.9)$ & $1.55(8.1)$ & $0.34(5.7)$ & $0.33(7.2)$ \\
3 & $1.13(9.4)$ & $1.52(11.6)$ & $0.38(10.1)$ & $0.39(23.1)$
\end{tabular}

${ }^{\text {a }}$ Figures in parentheses represent standard deviation $\sigma$ $(\%) ; 100 \sqrt{\sum\left(x_{i}-\bar{x}\right)^{2} / n} / \bar{x}$.

Table VIII. Penultimate model reactivity ratios $r_{i j}$ in the copolymerization of MMA $\left(\mathrm{M}_{1}\right)$ and AN $\left(\mathrm{M}_{2}\right)$ in DMSO at $50^{\circ} \mathrm{C}$ determined from comonomer sequence analysis ${ }^{\mathbf{a}}$

\begin{tabular}{ccccccc}
\hline & \multicolumn{3}{c}{ MMA content } & & & \\
Sample & \multicolumn{2}{c}{$r_{11}$} & $r_{21}$ & $r_{12}$ & $r_{22}$ \\
\cline { 2 - 3 } & \multirow{2}{*}{ Feed } & Copolymer & & & & \\
\hline 4 & 0.205 & 0.365 & 1.49 & 1.58 & 0.32 & 0.32 \\
5 & 0.347 & 0.515 & 1.32 & 1.46 & 0.36 & 0.33 \\
6 & 0.398 & 0.564 & 1.23 & 1.43 & 0.34 & 0.34 \\
7 & 0.453 & 0.610 & 1.13 & 1.49 & 0.35 & 0.36 \\
8 & 0.508 & 0.645 & 1.09 & 1.36 & 0.37 & 0.38 \\
9 & 0.548 & 0.679 & 1.12 & 1.45 & 0.37 & 0.45 \\
$10^{\mathrm{b}}$ & 0.548 & 0.678 & 1.08 & 1.39 & 0.36 & 0.41 \\
$11^{\mathrm{c}}$ & 0.548 & 0.675 & 1.06 & 1.46 & 0.38 & 0.43 \\
$12^{\mathrm{d}}$ & 0.548 & 0.672 & 1.07 & 1.41 & 0.39 & 0.42 \\
& & & & & &
\end{tabular}

${ }^{a}$ Copolymerizations were carried out in DMSO at $50^{\circ} \mathrm{C}$ and at $[\mathrm{MMA}+\mathrm{AN}]_{0}=5 \mathrm{~mol}^{-1}$ and $[\mathrm{MMA}+\mathrm{AN}]_{0} /$ $[\mathrm{AIBN}]_{0}=150$ except for samples $10-12$. For samples $10-12$, see footnotes $\mathrm{b}-\mathrm{d} \cdot{ }^{\mathrm{b}}[\mathrm{MMA}+\mathrm{AN}]_{\mathrm{o}} /[\mathrm{AIBN}]_{0}=$ 75. ${ }^{\mathrm{c}}$ Polymerization temperature $60^{\circ} \mathrm{C}$. ${ }^{\mathrm{d}}$ Polymerization temperature $40^{\circ} \mathrm{C}$.

range with higher MMA contents ( $c f$. Table VIII). The results indicate that there exists prepenultimate effect but no penultimate one in the reactivity of $\mathrm{AN}$ chain-end radical in this 
copolymerization. The pre-penultimate effect without penultimate one may be caused by a peculiar structure of the propagating radicals, such as the radicals stabilized by the prepenultimate substituent. Further studies are needed for clarifying this problem.

The fluctuation of monomer reactivity ratios is affected by that of results of copolymerization. In order to study the reproducibility and precision of the results of the copolymerization, additional runs of the copolymerization were made under various conditions including those adopted for copolymer samples $1-3$ shown in Table I. ${ }^{13} \mathrm{C}$ NMR analyses of these copolymers were performed on a $125 \mathrm{MHz}$ NMR spectrometer in Hatada's laboratory. The penultimate model reactivity ratios obtained from the ${ }^{13} \mathrm{C}$ NMR spectra of these copolymer samples are shown in Table VIII. The analyses of three copolymer samples 4, 5, and 9 in Table VIII, each of which was prepared under the same conditions as those for samples 1, 2, and 3 , respectively, showed the reactivity ratios very close to those of the corresponding samples among the latter copolymers ( $c f$. Table VII). This is the clear indication of excellent reproducibility of the polymerization reaction as well as of evaluation of the monomer reactivity ratios. All the reactivity ratios for six different copolymers (samples 4-9 in Table VIII) depend on the copolymer compositions; the $r_{11}$ and $r_{21}$ values decrease and the $r_{12}$ and $r_{22}$ values increase with an increase in the MMA content of the copolymer. The results are consistent with those shown in Table VII.

The extent of peak separation might depend on the composition, particularly in case that the peak separation is not good enough, i.e., methine carbon region ( $c f$. Figure 2). Thus, there may be composition-dependent systematic artifacts in the determination of the monomer sequence distribution and, as a consequence, in that of monomer reactivity ratios. To clarify such a possibility, the analysis of the spectrum obtained at higher magnetic field would be useful. Thus additional measure-
Table IX. Determination of penultimate model reactivity ratios $r_{i j}$ for the copolymerization of MMA $\left(M_{1}\right)$ and AN $\left(M_{2}\right)$ in DMSO at $50^{\circ} \mathrm{C}$ from $150 \mathrm{MHz}{ }^{13} \mathrm{C}$ NMR spectra

\begin{tabular}{ccccc}
\hline Sample & $r_{11}$ & $r_{21}$ & $r_{12}$ & $r_{22}$ \\
\hline 1 & 1.45 & 1.58 & 0.32 & 0.36 \\
2 & 1.38 & 1.51 & 0.35 & 0.34 \\
3 & 1.20 & 1.45 & 0.37 & 0.42 \\
\hline
\end{tabular}

ments were made at one test site (Osaka University) on a $600 \mathrm{MHz}$ spectrometer (Varian UNITY-plus 600) at $150 \mathrm{MHz}$. The results are shown in Table IX, which also indicate the composition dependence of $r_{i j}$.

As shown in Table VIII, the temperature of copolymerization scarcely affects the results of copolymerization within the experimental error at least in the temperature range of $40-60^{\circ} \mathrm{C}$ (samples 9,11 , and 12). The ratio of monomer and initiator concentrations (samples 9 and 10) also does not affect the results. This clearly indicates that the fluctuation of temperature or concentration of the reagents, even if it exists, hardly affects the values of monomer reactivity ratios. Then, all the results in Table VIII show the reliability of the results in Table VII. More detailed studies are required for the clarification of the existence of prepenultimate effect.

In the case of the copolymerization with penultimate or pre-penultimate effect, terminal model reactivity ratios, $r_{1}$ and $r_{2}$, are meaningless. However, these values were determined from the copolymer compositions shown in Table $\mathrm{V}$ by Fineman-Ross method for reference. The $r_{1}$ and $r_{2}$ values thus obtained were 1.38 and 0.32 , respectively, on average. The former is in an intermediate between $r_{11}$ and $r_{21}$, while the latter is not larger than either of $r_{12}$ or $r_{22}$. The $\sigma$ values for the $r_{1}(23.6 \%)$ and $r_{2}(21.8 \%)$ are larger than those for the $r_{i j}$.

\section{REFERENCES}

1. R. Chûjô, K. Hatada, R. Kitamaru, T. Kitayama, 
H. Sato, and Y. Tanaka, Polym. J., 19, 413 (1987).

2. R. Chûjô, K. Hatada, R. Kitamaru, T. Kitayama, H. Sato, Y. Tanaka, F. Horii, and Y. Terawaki, Polym. J., 20, 627 (1988).

3. F. Horii, M. Nakagawa, R. Kitamaru, R. Chûjô, K. Hatada, and Y. Tanaka, Polym. J., 24, 1155 (1992).

4. R. Chûjô, J. Phys. Soc. Jpn., 21, 2669 (1966).
5. R. Chûjô, H. Ubara, and A Nishioka, Polym. J., 3, 670 (1972).

6. T. Gerken and W. M. Ritchey, J. Appl. Polym. Sci., Appl. Polym. Symp., 34, 17 (1978).

7. V. U. Johnsen and K. Kolbe, Makromol. Chem., 116, 173 (1968). 